\title{
Nicorandil preserves blood-brain barrier and improves memory impairment in hypertensive rats
}

\author{
Zatiye Ayça ÇEVIKELLİ YAKUT 1 (D), Büşra ERTAŞ ${ }^{1}$ (D), Türkan KOYUNCUOĞLU 2 (D), \\ Berrak Ç. YEĞEN 2 (D), Göksel ŞENER 1* (D)
}

1 Department of Pharmacology, Faculty of Pharmacy, Marmara University, Haydarpaşa 34668 İstanbul, Turkey.

2 Department of Physiology, Faculty of Medicine, Marmara University, Maltepe 34854 İstanbul, Turkey.

* Corresponding Author. E-mail: gsener@marmara.edu.tr (G.S..); Tel. 00-90-216-414-29-62.

Received: 10 September 2019 / Revised: 05 October 2019 / Accepted: 22 October 2019

\begin{abstract}
In renovascular hypertension (RVH), oxidative stress and inflammation due to high blood pressure and elevated levels of angiotensin 2 are mainly responsible of cerebrovascular complications and impaired cognitive functions. Since the nicorandil has been shown to exert neuroprotective, anti-inflammatory and antioxidant effects, we investigated the effect of nicorandil against vascular dementia and blood brain barrier damage in a rat model of angiotensin-dependent hypertension. Wistar albino rats, were divided as sham-operated control, renovascular hypertension (RVH) and Nicorandil-treated RVH groups. Silver clip was implanted onto the left renal artery. Using the tail-cuff method, blood pressure of rats was measured before the surgery and at the end of the post-surgical $3^{\text {rd }}$ and $12^{\text {th }}$ weeks. Nicorandil ( $4 \mathrm{mg} / \mathrm{kg}$, orally) or vehicle was administered for 9 weeks. Twelve weeks after RVH surgery, a new object recognition test was performed. Following the determination of blood brain barrier integrity, serum samples were taken for the evaluation of proinflammatory cytokines tumor necrosis alpha (TNF- $\alpha$ ) and interleukin-1 beta (IL$1 \beta)$. Levels of sodium-potassium adenosine triphosphatase $\left(\mathrm{Na}^{+} / \mathrm{K}^{+}\right.$-ATPase), as a marker of endothelial damage, were evaluated in the hippocampal tissues. RVH resulted in significant increases in TNF- $\alpha$ and IL-1 $\beta$ levels and decreases in $\mathrm{Na}^{+} / \mathrm{K}^{+}$-ATPase levels, along with impairment in blood brain barrier integrity and memory performance. In the nicorandil treatment group, these indices were reversed back to control levels. The present data demonstrated that nicorandil attenuates RVH-induced memory impairment and blood brain barrier damage in rats with RVH.
\end{abstract}

KEYWORDS: Renovascular hypertension; angiotensin 2; nicorandil; blood brain barrier; vascular dementia.

\section{INTRODUCTION}

Reduction in renal blood flow, which increases the activity of renin angiotensin system, results in renovascular hypertension (RVH) or so-called angiotensin II (A-II) -dependent hypertension [1]. High blood pressure and increased A-II levels lead to serious vascular complications such as extracellular matrix accumulation in vascular wall, vascular remodeling and atherogenesis in the long-term, which further exacerbate the detrimental effects of high blood pressure on the vascular structure [2- 4]. In addition, experimental studies support that A II induces the production of reactive oxygen species (ROS) [5-8], which through damaging endothelium, increase contractility and contribute to hypertrophy and inflammation in the cerebral vessels [9]. Due to the structural changes in the cerebral vasculature, disruption of the blood brain barrier (BBB) and consequently impairment in cognitive functions are inevitable $[10,11]$ and elevate the risk of vascular dementia.

Increased ROS production enhances BBB permeability by activating metalloproteases (MMP) [12]. These proteases further activate inflammatory cytokines, such as tumor necrosis factor alpha (TNF- $\alpha$ ), interleukin (IL)-1 beta ( $\beta$ ) and IL-6, which devastate the BBB $[13,14]$. The observation of impaired BBB permeability in patients with mild cognitive impairment or dementia supported the relationship between BBB injury and cognitive impairment $[15,16]$.

Another pathophysiologic change related with vascular dementia due to disrupted BBB is, decreased sodium-potassium adenosine triphosphatase $\left(\mathrm{Na}^{+} / \mathrm{K}^{+}\right.$-ATPase) activity [17]. In $\mathrm{RVH}$, damage in endothelium and neuronal membrane due to enhanced generation of ROS and cytokines results in depressed $\mathrm{Na}^{+} / \mathrm{K}^{+}$ ATPase enzyme activity $[17,18]$. Accordingly, increased intracellular $\mathrm{Na}^{+}$levels inhibit the $\mathrm{Na}^{+} / \mathrm{Ca}^{+2}$ channel exchanger and intracellular $\mathrm{Ca}^{+2}$ levels become elevated. High levels of intracellular $\mathrm{Ca}^{+2}$ further augment inflammatory cytokine levels, trigger vasoconstriction, and decrease cerebral blood flow [19]. On the other

How to cite this article: Çevikelli Yakut ZA, Ertaş B, Koyuncuoğlu T, Yeğen BÇ, Şener G. Nicorandil preserves blood-brain barrier and improves memory impairment in hypertensive rats. J Res Pharm. 2019; 23(6): 1140-1148. 
hand, while potassium efflux from the $\mathrm{K}^{+}$channels in cerebrovascular smooth muscle cells increases vasodilatation and perfusion [20], potassium efflux in neurons is also known to reduce the glutamate and calcium in the neuron, via membrane hyperpolarization [21].

Nicorandil which carries organic nitrate and nicotinamide in its chemical structure is a KATP channel agonist. It has been used as an effective antianginal drug for a long time [22]. Nicorandil leads to vasodilatation through releasing NO and opening the KATP channels which is also observed in the cardiac muscle membrane [23]. Singh et al. suggested that nicorandil may be beneficial in the treatment of memory impairment in angiotensin-dependent hypertension model through its vasodilator, antiinflammatory, antioxidant and neuroprotective effects [24]. Nicorandil, through opening KATP channels in neurons and cerebral vessels in the brain, can avoid or reduce the ischemic damage [25]. In addition, nicorandil has been shown to protect the neurons against inflammation by reducing the release of proinflammatory mediators, such as TNF- $\alpha$, IL- $1 \beta$ and IL-6 [26, 27]. In an in vitro model, nicorandil suppressed the increased TNF- $\alpha$, IL-1 $\beta$ levels due to oxygenglucose deprivation [27]. Morever, Heurteaux et al. demonstrated the neuroprotective effect of nicorandil treatment against transient global forebrain ischemia in rats [28]. In addition, nicorandil has been also shown to exert antioxidative effects through the inhibition of nicotinamide adenine dinucleotide phosphate (NADPH) oxidase and lipid peroxidation [29]. Moreover, nicorandil enhances nitric oxide (NO) levels by upregulating the expression of endothelial NO synthase (eNOS) [30].

In the light of above findings, we aimed to investigate whether nicorandil, through its neuroprotective, anti-inflammatory and antioxidant effects, could alleviate renovascular hypertension-induced memory impairment and blood brain barrier disruption.

\section{RESULTS}

\subsection{Blood pressure}

The basal blood pressure that was recorded before surgery was not different among the groups (Figure $1)$. In the RVH group, the mean systolic blood pressure was significantly elevated at $3^{\text {rd }}(p<0.001)$ and $12^{\text {th }}$ $(\mathrm{p}<0.001)$ weeks with respect to basal values. In the nicorandil-treated RVH group, in which the treatment was not yet started the $3^{\text {rd }}$ week records of mean blood pressure were also elevated $(\mathrm{p}<0.001)$. However, following the 9-week treatment with nicorandil systolic blood pressure was reduced significantly as compared with that of the $3^{\text {rd }}$ week $(\mathrm{p}<0.001)$.
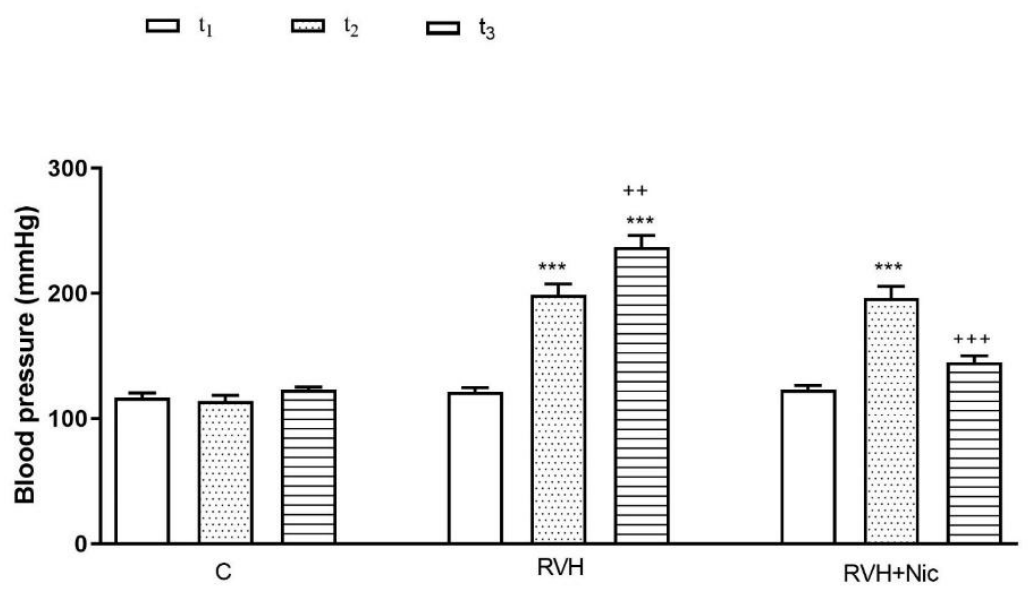

Figure 1. Systolic blood pressure values at baseline $\left(t_{1}\right), 3$ weeks $\left(t_{2}\right)$ and 9 weeks $\left(t_{3}\right)$ after saline or nicorandil treatment. ${ }^{* * *} \mathrm{p}<0.001$ : according to initial values; $++\mathrm{p}<0.01,+++\mathrm{p}<0.001$ : Comparisons based on 3-week measurements.

\subsection{New object recognition test}

Results of the new object recognition test revealed that the animals in the saline-treated RVH group had a significantly reduced memory performance with respect to that of the sham-operated control group ( $\mathrm{p}<$ 0.001; Figure 2). However, the memory performances of the nicorandil-treated RVH rats were significantly improved $(\mathrm{p}<0.001$, Figure 2). 


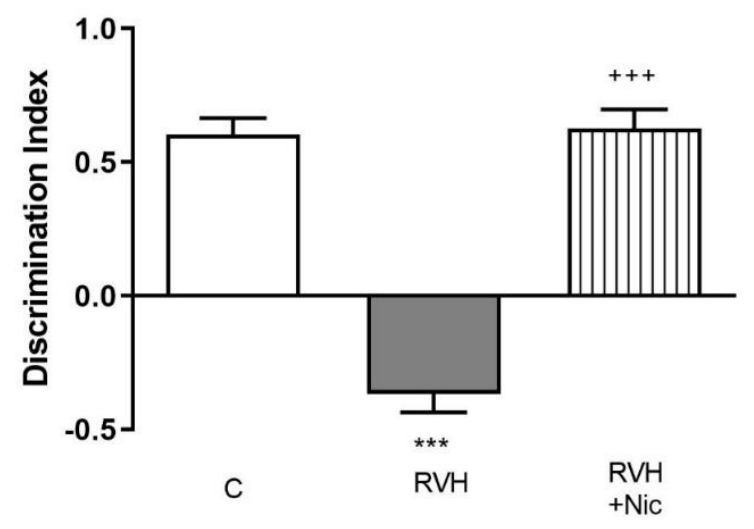

Figure 2. Discrimination indices showing the performances in novel object recognition test of all groups. ${ }^{* * *}$ $\mathrm{p}<0.001$ : compared to the control group; $+++\mathrm{p}<0.001$ : compared to RVH group.

\subsection{Serum tumor necrosis factor alpha and interleukin 1-beta levels}

Serum TNF-a levels were found to be higher in RVH group $(\mathrm{P}<0.001)$ than those of the sham-operated control group. In the nicorandil-treated RVH group, TNF- $\alpha$ levels $(p<0.01)$ were significantly decreased when compared with saline-treated RVH group (Figure 3a). Accordingly, RVH caused an elevation in serum IL-1 $\beta$ levels as compared to the sham-operated control group $(p<0.01)$, while nicorandil treatment significantly depressed the IL-1 $\beta$ levels $(\mathrm{p}<0.05)$ (Figure 3b).

a)

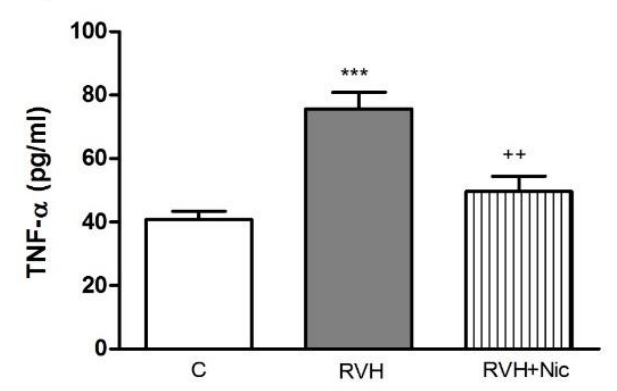

b)

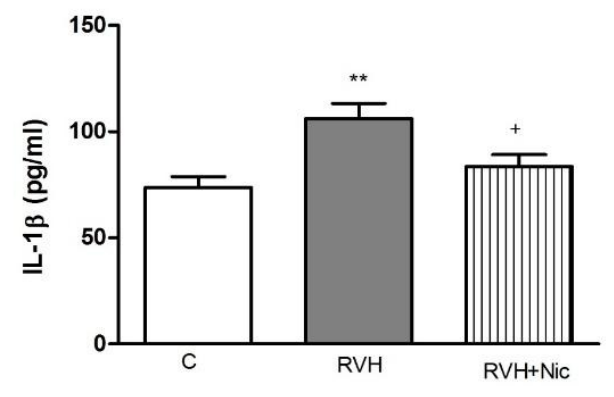

Figure 3. A) Serum TNF- $\alpha$ and B) IL-1 $\beta$ levels in all experimental groups. ${ }^{* *} p<0.01,{ }^{* * *} p<0.001$ : compared to the control group; $+p<0.05,++p<0.01$ : compared to RVH group.

\subsection{Brain tissue $\mathrm{Na}^{+} / \mathrm{K}^{+}-\mathrm{ATPase}$ levels}

Hippocampal $\mathrm{Na}^{+} / \mathrm{K}^{+}$-ATPase levels were significantly decreased in the saline-treated $\mathrm{RVH}$ group $(\mathrm{p}<$ 0.001 ) with respect to sham-operated control group. On the other hand, nicorandil treatment given to $\mathrm{RVH}$ group alleviated this decrement $(\mathrm{p}<0.01)$ (Figure 4$)$. 


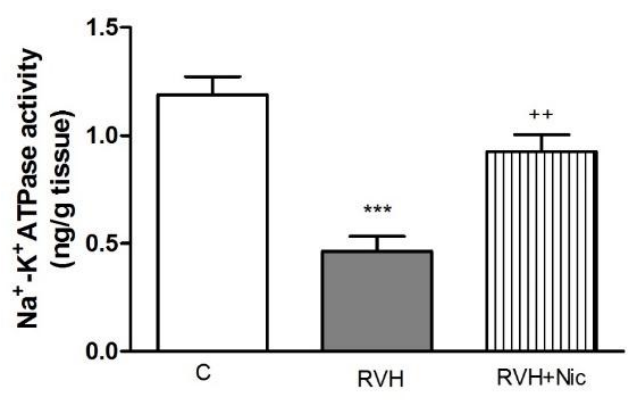

Figure 4. Hippocampal $\mathrm{Na}^{+} / \mathrm{K}^{+}$-ATPase levels in all experimental groups. . ${ }^{* * *} \mathrm{p}<0.001$ : compared to the control group; $++p<0.01$ : compared to the RVH group.

\subsection{Blood brain barrier permeability}

As compared to the sham-operated control group, EB content of the brain was significantly increased in the saline-treated RVH group ( $p<0.001$, Figure 5), indicating an enhanced extravasation due to break down of BBB integrity. A significantly reduced EB content was observed in the nicorandil-treated RVH group ( $\mathrm{p}<$ $0.001)$, but it was still higher than that of the sham-operated control group $(\mathrm{p}<0.05)$.

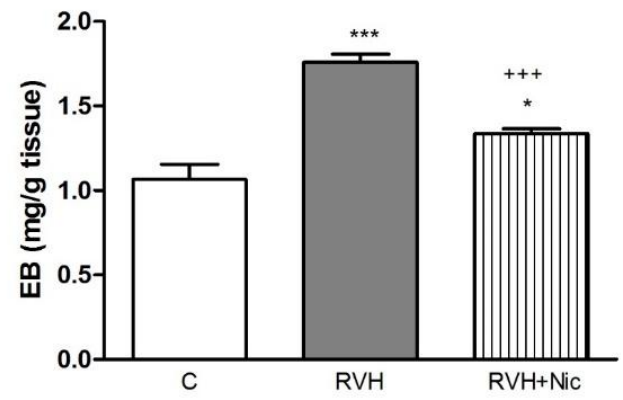

Figure 5. Evans blue (EB) extravasation in the brain tissues of all experimental groups. ${ }^{*} \mathrm{p}<0.05$, ${ }^{* * *} \mathrm{p}<0.001$ : compared to the control group; $+++p<0.001$ : compared to RVH group.

\section{DISCUSSION}

The results of the current study demonstrate that the sustained high blood pressure due to RVH led to short-term memory impairment and blood brain barrier disruption through a cytokine-induced inflammatory response that also affects the hippocampal membrane stability. On the other hand, the results of the current study suggest that nicorandil treatment exerts neuroprotective effects on RVH-induced inflammation and cerebral injury, and thereby alleviates the cerebral complications of prolonged hypertension.

Our study indicated that high blood pressure promotes inflammation as it was demonstrated with high serum inflammatory cytokine levels in the RVH group. Along with its blood pressure lowering effect, nicorandil treatment reduced serum inflammatory cytokine levels. Supportive of this data, reports of previous experimental studies have suggested that, cerebral endothelium is exposed to mechanical stress in RVH, during which the high blood pressure over-stimulates the mechanoreceptors, [31]. Lan et al (2004) have reported that shear stress activates nuclear factor kappa-B (NFKB) pathway, which then triggers NADPH oxidase and xanthine oxidase gene expression, and consequently enhances ROS production [31,32]. Activation of the NFKB pathway also increases the expression of proinflammatory cytokines, including TNF- $\alpha$, IL-1 $\beta$ [33].

It has been known for many years that A-II is found in high blood levels in $\mathrm{RVH}$, and in addition to its blood pressure-elevating effects A-II damages cerebral endothelium in many ways. In the current study, poor cognitive function of the RVH rats with a prolonged period of hypertension encourages this hypothesis. In $\mathrm{RVH}$, local A-II generation in cerebral vessels is also facilitated as an adaptive hypertrophic response to high blood pressure [34]. Oxidative stress, inflammation and cell hypertrophy on cerebral endothelium are detrimental effects of A-II that cause cerebral hypoperfusion and trigger vascular dementia. First of all A-II increases ROS production by activating NADPH oxidase through A-II type 1 receptor (AT1R) on cerebral 
endothelium [35]. Secondarily, A-II triggers cell hypertrophy and proliferation in cerebral endothelium through the increased generation of autocrine and paracrine growth factors, such as fibroblast growth factor (FGF), platelet derived growth factor (PDGF), vascular endothelial growth factor (VEGF), transforming growth factor beta (TGF $\beta$ ). Moreover, A-II promotes cerebral vessel inflammation in all stages of inflammation. A-II elevates vascular permeability and also promotes the adhesion of monocytes, leukocytes and neutrophils to cerebral endothelium cells by upregulating the expressions of adhesion molecules, e.g. selectins and vascular cell adhesion molecules (VCAM)-1. Another important mechanism that explains the relationship between A-II and cerebral inflammation is that A-II increases the expressions of TNF- $\alpha$, IL-1 $\beta$ and IL-6 genes in macrophages [33] by activating NFKB and Rho/Rho kinase pathways [36, 37]. It is well known that pro-inflammatory cytokines damage cerebral endothelium with several mechanisms. In cultured human epithelial cancer cells, it was demonstrated that both TNF- $a$ and IL-6 stimulate endothelial cell growth and migration [38]. Various studies have shown that pro-inflammatory cytokines trigger apoptosis, increase the generation of ROS and MMPs, which promote the degradation of collagen, elastin and other components of cerebral endothelial cells [39, 40,41]. Results of the current study showed that high serum inflammatory cytokine levels in RVH along with poor cognitive functions is a predictor of cerebral endothelium damage. On the other hand, nicorandil treatment with its anti-inflammatory, antioxidant, vasodilator effects could have enhanced cerebral blood flow, which may have then improved cognitive functions of RVH rats assessed by a short- memory recall test. Similarly, in the RVH-induced vascular dementia model, Singh et al. has found that nicorandil reduced the thiobarbituric acid reactive substance (TBARS) levels, an oxidative stress biomarker in serum and brain and, increased antioxidant levels. In the same study, nicorandil improved cognitive functions in short and long memory recall tests. [24]. Furthermore, in the chronic central hypoperfusion animal model similar results were found with nicorandil treatment [42].

BBB, composed of specialized endothelial cells interconnected by tight junctions, restricts the passage of substances between the circulatory and central nervous systems. Biancardi et al (2014) have demonstrated that spontaneous hypertensive rats, as well as renovascular hypertensive rats, have a disrupted BBB [43]. The results of our study are in agreement with these previous studies. Microvessel culture studies have shown that AT1R activation increases BBB permeability [44, 45]. Inflammatory IL-1 $\beta$, and TNF- $\alpha$, which are shown to increase in the circulation of RVH rats also disrupt the integrity of BBB [46, 47]. Another mechanism that damages the BBB in RVH is the disintegration of adventitia layer in the cerebral vascular endothelium by MMP enzymes, which are activated by inadequate cerebral blood flow. In our study, it appears that nicorandil treatment prevented the impairment of BBB due to its anti-inflammatory effects in conjunction with its cerebral blood flow-enhancing effects.

The extracellular $\mathrm{K}^{+}$concentration is crucial in the excitable cells, including the neurons [48]. $\mathrm{Na}^{+} / \mathrm{K}^{+}$ ATPase, an essential enzyme responsible for the control of electrochemical gradient, maintains the normal gradient of sodium and potassium ions across the cell membranes. Reduction of $\mathrm{Na}^{+} / \mathrm{K}^{+}$-ATPase activity, as in ischemic conditions, causes an ionic unbalance, deteriorates various neurotransmitters and triggers hypoxia and inflammation, resulting in cognitive defects [49]. The results of current study showed that depletion of $\mathrm{Na}^{+} / \mathrm{K}^{+}$-ATPase levels in the hippocampi of in RVH rats was accompanied by apparent cognitive defects. Since nicorandil treatment preserved the $\mathrm{Na}^{+} / \mathrm{K}^{+}$-ATPase levels and improved the impaired memory function, it may be suggested that this beneficial impact of nicorandil may be due to its modulatory effects on cerebral endothelium.

\section{CONCLUSION}

In conclusion, our results demonstrate that nicorandil treatment reduces blood pressure, protects cerebral endothelial function and improves memory performance through its anti-inflammatory and BBBpreserving effects. Although further experimental and clinical studies are required, the findings advocate the use of nicorandil as a potential therapeutic agent in preventing hypertension-related cognitive defects.

\section{MATERIALS AND METHODS}

\subsection{Animals and ethics}

Male and female Wistar Albino rats (200-300 g) were housed in an air-conditioned room with $12 \mathrm{~h}$ light and dark cycles, where the temperature $\left(22 \pm 2^{\circ} \mathrm{C}\right)$ and relative humidity $(65-70 \%)$ were kept constant. They were obtained from Marmara University (MU) Research Center for Experimental Animals (DEHAMER). All experimental protocols were approved by the MU Animal Care and Use Committee (\#52.2019.mar). 


\subsection{Surgery and experimental protocol}

Rats were divided into three groups, each consisting of fourteen animals: Sham-operated control, renovascular hypertension $(\mathrm{RVH})$ and nicorandil-treated $\mathrm{RVH}$ groups. To induce anesthesia, rats were injected intraperitoneally with $100 \mathrm{mg} / \mathrm{kg}$ ketamine and $0.75 \mathrm{mg} / \mathrm{kg}$ chlorpromazine. A silver clip (internal diameter $0.25 \mathrm{~mm}$ ) was placed around the left renal artery of the rats $[2,50]$. In the sham-operated control group, the rats underwent a similar surgical procedure without clip insertion. Starting at 3 weeks following surgery, rats were treated perorally with either saline (control and RVH groups) or nicorandil $(4 \mathrm{mg} / \mathrm{kg}$, $\mathrm{RVH}+\mathrm{Nic}$ ) for 9 weeks. The rationale for the used dose of nicorandil is based on a previous study, where the therapeutic effects of nicorandil were observed in a RVH-induced vascular dementia [22]. Twelve weeks after RVH surgery, a "new-object recognition test" was performed. At the end of the experiment, 6 animals from each group were used for the assessment of blood brain barrier permeability. Rest of the animals in each group $(n=8)$ were decapitated to obtain, hippocampal tissues and serum samples. All samples were stored at $-80^{\circ} \mathrm{C}$ for biochemical analyses.

\subsection{Blood pressure measurement}

Indirect blood pressure (BP) measurement was made by the tail-cuff method. Initially, the rats were placed in a chamber heated to $35^{\circ} \mathrm{C}$ for $10 \mathrm{~min}$. Then the rats were placed in individual plastic restrainers and a cuff with a pneumatic pulse sensor was wrapped around their tails (Biopac MP35 Systems, Inc. COMMAT Ltd., Ankara, Turkey). Blood pressures were recorded before surgery (t1), at the third week ( $\mathrm{t} 2)$, and at the end of the 12 weeks (t3). During each measurement session, at least three consecutive readings obtained from each rat and the average was used as the record of that animal [50].

\subsection{Biochemical analysis}

\subsubsection{Chemicals}

Nicorandil was obtained from Santa Cruz Biotechnology, Inc. (California, USA). Rat IL-1ß ELISA Kit, Rat TNF-a ELISA Kit and Rat $\mathrm{Na}^{+} / \mathrm{K}^{+}$-ATPase ELISA Kit were obtained from YL Biotech Co. (Shanghai, China). Evans blue was obtained from Sigma Chemical Co. (St Louis, MO, USA).

\subsubsection{Measurement of the levels of serum cytokines and hippocampal $\mathrm{Na}^{+} / \mathrm{K}^{+}-\mathrm{ATPase}$}

Serum TNF- $\alpha$ and IL-1 $\beta$, and hippocampal $\mathrm{Na}^{+} / \mathrm{K}^{+}$-ATPase levels were quantified according to the manufacturer's instructions and guidelines of the enzyme-linked immunosorbent assay (ELISA) kits specific for rats (YL Biotech Co. Shanghai, China).

\subsubsection{Evans blue assay for the evaluation of blood brain barrier permeability}

Six animals from each group were used for blood brain barrier permeability assessment. To evaluate the blood brain barrier (BBB) integrity, Evans blue dye (EB) was used as a marker of albumin extravasation [51]. Briefly, EB (2\% in saline, $4 \mathrm{ml} / \mathrm{kg}$ ) was injected via the jugular vein and was allowed to circulate for 30 $\mathrm{min}$. Then, chests were opened and the rats were perfused transcardially for approximately $15 \mathrm{~min}$ with a 250 $\mathrm{ml}$ of saline at a pressure of $110 \mathrm{~mm} \mathrm{Hg}$. After decapitation, the brain tissues were removed and weighed for the quantitative measurement of EB-albumin extravasation. Brain samples were homogenized in a $2.5 \mathrm{ml}$ phosphate-buffered saline and mixed by vortexing for $2 \mathrm{~min}$ after the addition of $2.5 \mathrm{ml}$ of $60 \%$ trichloroacetic acid to precipitate the proteins. Samples were cooled and then centrifuged for $30 \mathrm{~min}$ at $1000 \mathrm{~g}$. Using a spectrophotometer (Shimadzu UV1208, Japan), the absorbance of EB in the supernatant was measured at 620 $\mathrm{nm}$. EB was calculated using a standard curve and was expressed as $\mathrm{mg} / \mathrm{g}$ of brain tissue.

\subsection{New object recognition test}

Twenty-four hours before the test session, animals were first allowed to acclimate to the environment (habituation phase). Animals of the same cage were placed together in the box $(31 \times 24 \times 45.5 \mathrm{~cm})$ that will be used for testing and were kept for one hour. During the training phase, each rat was put for 3 minutes in the same box, where two objects $(\mathrm{A}+\mathrm{A})$ of the same kind were placed, and its activity was were recorded by a video camera. Then the rat was returned to its home cage. An hour later, the rat was observed and video-taped for 3 minutes in the box containing the old and a new object $(A+B)$ (test phase). During all experiments, the box and objects were cleaned with $70 \%$ alcohol solution before the test of the next animal [52]. 
For the assessment, time spent for exploring new and old objects were recorded in seconds and the discrimination index (DI) was calculated using the formula, where Tn is the time to explore new object and To is the time to explore old object: DI : $(\mathrm{Tn}-\mathrm{To}) /(\mathrm{Tn}+\mathrm{To})$.

\subsection{Statistical analysis}

Statistical analysis was performed using GraphPad Prism 6.0 (GraphPad Software, San Diego, CA, USA). Each group consisted of fourteen animals. Six animals from each group were used for BBB permeability assessment and eight animals from each group were used for other biochemical analyses. All data are expressed as the mean \pm SEM. The Mann-Whitney U-test was used to evaluate scores of the new object recognition test. Biochemical data was analyzed with ANOVA followed by Turkey's multiple comparison tests. Statistical significance was accepted as $\mathrm{p}<0.05$.

Acknowledgements: This study was supported by Marmara University, BAPKO foundation (Project No: SAG-C-DRP120418-0159).

Author contributions: Concept - G.Ş., Z.A.Ç.Y.; Design - G.Ş., Z.A.Ç.Y.; Supervision - Z.A.Ç.Y., G.Ş.; Resources Z.A.Ç.Y., B.E., G.Ş., T.K.; Materials - Z.A.Ç.Y., T.K., G.Ş.; Data Collection and/or Processing - Z.A.Ç.Y., B.E., G.Ş.; Analysis and/or Interpretation - Z.A.Ç.Y., B.Ç.Y., G.Ş.; Literature Search - Z.A.Ç.Y., G.Ş.; Writing - Z.A.Ç.Y., B.Ç.Y., G.Ş.; Critical Reviews - Z.A.Ç.Y., B.E., T.K., B.Ç.Y., G.Ş.

Conflict of interest statement: The authors declare that they have no conflict of interest.

\section{REFERENCES}

[1] Samadian F, Dalili N, Jamalian A. New Insights Into Pathophysiology, Diagnosis, and Treatment of Renovascular Hypertension. Iran J Kidney Dis. 2017; 11(2): 79-89.

[2] Erşahin M, Sehirli O, Toklu HZ, Süleymanoglu S, Emekli-Alturfan E, Yarat A, Tatlidede E, Yeğen BC, Sener G. Melatonin improves cardiovascular function and ameliorates renal, cardiac and cerebral damage in rats with renovascular hypertension. J Pineal Res. 2009; 47(1): 97-106. [CrossRef]

[3] Bromfield S, Muntner P. High blood pressure: the leading global burden of disease risk factor and the need for worldwide prevention programs. Curr Hypertens Rep. 2013; 15(3): 134-136. [CrossRef]

[4] World Health Organization. A global brief on hypertension: silent killer, global public health crisis. http://www.who.int/ cardiovascular_diseases/publications/global_brief_hypertension/en/2013. [accessed April $21,2016]$.

[5] Faconti L, Bruno RM, Ghiadoni L, Taddei S, Virdis A. Ventricular and vascular stiffening in aging and hypertension. Curr Hypertens Rev. 2015; 11: 100-109.

[6] Zafari AM, Ushio-Fukai M, AkersMet al. Role of NADH/ NADPH oxidase-derived H2O2 in angiotensin II-induced vascular hypertrophy. Hypertension. 1998; 32: 488-495. [CrossRef]

[7] Laursen JB, Rajagopalan S, Galis Z, Tarpey M, Freeman BA, Harrison DG. Role of superoxide in angiotensin-IIinduced but not catecholamine-induced hypertension. Circulation. 1997; 95: 588-593. [CrossRef]

[8] Somers MJ, Mavromatis K, Galis ZS, Harrison DG. Vascular superoxide production and vasomotor function in hypertension induced by deoxycorticosterone acetate-salt. Circulation. 2000; 101:1722-1728. [CrossRef]

[9] Diep QN, Amiri F, Touyz RM, Cohn JS, Endemann D, Neves MF, Schiffrin EL. PPAR alpha activator effects on Ang II-induced vascular oxidative stress and inflammation. Hypertension. 2002; 40: 866-871. [CrossRef]

[10] Ushio-Fukai M, Zafari AM, Fukui T, Ishizaka N, Griendling KK. p22phox is a critical component of the superoxidegenerating NADH/NADPH oxidase system and regulates angiotensin II-induced hypertrophy in vascular smooth muscle cells. J Biol Chem. 1996; 271: 23317-23321. [CrossRef]

[11] Intengan HD, Schiffrin EL. Vascular remodeling in hypertension: roles of apoptosis, inflammation, and fibrosis. Hypertension. 2001; 38: 581-587. [CrossRef]

[12] Rosenberg GA, Wallin A, Wardlaw JM, Markus HS, Montaner J, Wolfson L, Iadecola C, Zlokovic BV, Joutel A, Dichgans M, Duering M, Schmidt R, Korczyn AD, Grinberg LT, Chui HC, Hachinski V. Consensus statement for diagnosis of subcortical small vessel disease. J Cereb Blood Flow Metab. 2016; 36: 6-25. [CrossRef]

[13] Coffman TM. Under pressure: the search for the essential mechanisms of hypertension. Nat Med. 2001; 17: 1402-1409. [CrossRef] 
[14] Winklewski PJ, Radkowski M, Wszedybyl-Winklewska M \& Demkow U. Brain inflammation and hypertension: the chicken or the egg? J Neuroinflammation. 2015; 12, 85. [CrossRef]

[15] Starr J.M, Farrall AJ, Armitage P, McGurn B, and Wardlaw J. Bloodbrain barrier permeability in Alzheimer's disease: a case-control MRI study. Psychiatry Res. 2009; 171, 232-241. [CrossRef]

[16] Taheri S, Gasparovic C, Huisa BN, Adair JC, Edmonds E, Prestopnik J. Blood-brain barrier permeability abnormalities in vascular cognitive impairment. Stroke. 2011; 42, 2158-2163. [CrossRef]

[17] de Lores Arnaiz GR, Ordieres MG. Brain Na(+), K(+)-ATPase Activity In Aging and Disease. Int J Biomed Sci. 2014; 10(2):85-102.

[18] Unterberg AW, Stover J, Kress B, Kiening KL. Edema and brain trauma. Neuroscience. 2004; 129: 1021-1029. [CrossRef]

[19] Masayo Koide, Adrian D. Bonev, Mark T. Nelson, and George C. Wellman. Inversion of neurovascular coupling by subarachnoid blood depends on large conductance Ca2+-activated K+ (BK) channels. PNAS. 2012; 109 (21): 1387 1395 [CrossRef]

[20] Kitazono T, Faraci FM, Taguchi H, Heistad DD. Role of potassium channels in cerebral blood vessels. Stroke. 1995; 26(9): 1713-23. [CrossRef]

[21] Liu FY, Cogan MG. Angiotensin II stimulation of hydrogen ion secretion in the rat early proximal tubule: Modes of action, mechanism, and kinetics. Clin Invest. 1988; 82: 601-607. [CrossRef]

[22] Tarkin JM, Kaski J. Nicorandil and Long-acting Nitrates: Vasodilator Therapies for the Management of Chronic Stable Angina Pectoris. Eur Cardiol. 2018; 13(1):23-28. [CrossRef]

[23] Kinoshita M, Sakai K. Pharmacology and therapeutic effects of nicorandil. Cardiovasc Drugs Ther. 1990; 4(4):107588. [CrossRef]

[24] Singh P, Gupta S, Sharma B. Melatonin receptor and KATP channel modulation in experimental vascular dementia. Physiol Behav. 2015; 142:66-78. [CrossRef]

[25] Kong J, Ren G, Jia N, Wang Y, Zhang H, Zhang W, Chen B, Cao Y. Effects of nicorandil in neuroprotective activation of PI3K/AKT pathways in a cellular model of Alzheimer's disease. Eur. Neurol. 2013; 70: 233-241. [CrossRef]

[26] Wei XM, Heywood GJ, Di Girolamo N, Thomas PS. Nicorandil inhibits the release of TNFalpha from a lymphocyte cell line and peripheral blood lymphocytes. Int. Immunopharmacol. 2003; 3: 1588. [CrossRef]

[27] Zhao AP, Dong YF, Liu W, Gu J, Sun XL. Nicorandil inhibits inflammasome activation and Toll-like receptor-4 signal transduction to protect against oxygen-glucose deprivation-induced inflammation in BV-2 cells. CNS Neurosci. Ther. 2014; 20: 147-153. [CrossRef]

[28] Heurteaux C, Bertaina V, Widmann C, and Lazdunski M. K+ channel openers prevent global ischemia-induced expression of c-fos, c-jun, heat shock protein, and amyloid (3-protein precursor genes and neuronal death in rat hippocampus. Neurobiology. 1993; 90(20):9431-9435. [CrossRef]

[29] Gupta S, Sharma B. Protective effects of phosphodiesterase-1 (PDE1) and ATP sensitive potassium (KATP) channel modulators against 3-nitropropionic acid induced behavioral and biochemical toxicities in experimental Huntington's disease, Eur. J. Pharmacol. 2014; 732: 122. [CrossRef]

[30] Horinaka S, Kobayashi N, Yabe A, Asakawa H, Yagi H, Mori Y, Tsubokou Y, Yoshida K, Nicorandil protects against lethal ischemic ventricular arrhythmias and up-regulates endothelial nitric oxide synthase expression and sulfonylurea receptor 2 mRNA in conscious rats with acute myocardial infarction, Cardiovasc. Drugs Ther. 2004; 18: 13-22. [CrossRef]

[31] Cachofeiro V, Miana M, de las Heras N, Martin- Fernandez B, Ballesteros S, Balfagon G, Lahera V. Inflammation: A Link Between Hypertension and Atherosclerosis. Current Hypertension Reviews. 2009; 5, 40-48. [CrossRef]

[32] Lan QX, Mercurius KO, Davies PF. Stimulation of Transcription Factors NFkB and AP1 in Endothelial Cells Subjected to Shear Stress. Biochemical and Biophysical Research Communications. 1994; 201(2): 950- 956. [CrossRef]

[33] Li N, Karin M. Is NFk $\beta$ the sensor of oxidative stress?. FASEB J. 1999; 13: 1137-43. [CrossRef]

[34] Ashby EL, Kehoe PG. Current status of renin-aldosterone angiotensin system-targeting anti-hypertensive drugs as therapeutic options for Alzheimer's disease. Expert Opin Investig Drugs. 2013; 22(10): 1229-42. [CrossRef]

[35] Ruiz-Ortega M, Rupérez M, Sánchez-López VEE, Rodríguez-Vita J, Carvajal G, Egido J. Angiotensin II as a novel proinflammatory factor in chronic diseases. Inflammation and Chronic Disease. 2006; 1-25. 
[36] Yamakawa T, Tanaka S, Numaguchi K, Yamakawa Y, Motley ED, Ichihara S, Inagami T. Involvement of Rho-kinase in angiotensin II-induced hypertrophy of rat vascular smooth muscle cells. Hypertension. 2000; 35: 313. [CrossRef]

[37] Matrougui K, Tanko LB, Loufrani L, Gorny D, Levy BI, Tedgui A, Henrion D. Involvement of Rho-kinase and the actin filament network in angiotensin II-induced contraction and extracellular signal-regulated kinase activity in intact rat mesenteric resistance arteries. Arterioscler Thromb Vasc Biol. 2001; 21: 1288. [CrossRef]

[38] Cohen T, Nahari D, Cerem LW, Neufeld G, Levi BZ. Interleukin 6 Induces the Expression of Vascular Endothelial Growth Factor. J Biol Chem. 1996;271:736-741. [CrossRef]

[39] Muzio M, Stockwell BR, Stennicke HR, Salvesen GS, Dixit VM. An induced proximity model for caspase-8 activation. J Biol Chem. 1998;273(5):2926-2930. [CrossRef]

[40] Madge LA, Pober JS. TNF signaling in vascular endothelial cells. Exp Mol Pathol. 2001;70(3):317-325. [CrossRef]

[41] Sprague AH, Khalil RA. Inflammatory Cytokines in Vascular Dysfunction and Vascular Disease. Biochem Pharmacol. 2009; 78(6): 539-552. [CrossRef]

[42] Gupta S, Singh P, Sharma B. Neuroprotective Effects of Nicorandil in Chronic Cerebral Hypoperfusion-Induced Vascular Dementia. J Stroke Cerebrovasc Dis. 2016; 25(11):2717-2728. [CrossRef]

[43] Biancardi VC, Son SJ, Ahmadi S, Filosa JA, Stern JE. Circulating angiotensin II gains access to the hypothalamus and brain stem during hypertension via breakdown of the blood-brain barrier. Hypertension. 2014; 63(3): 572-9. [CrossRef]

[44] Biancardi VC, Stern JE. Compromised blood-brain barrier permeability: novel mechanism by which circulating angiotensin II signals to sympathoexcitatory centres during hypertension. J Physiol. 2016; 594(6): 1591-1600. [CrossRef]

[45] Fleegal-DeMotta MA, Doghu S, Banks WA. Angiotensin II modulates BBB permeability via activation of the AT(1) receptor in brain endothelial cells. J Cereb Blood Flow Metab. 2009; 29(3): 640-7. [CrossRef]

[46] Setiadi A, Korim WS, Elsaafien K, Yao ST. The role of the blood-brain barrier in hypertension. Experimental Physiology. 2018; 103(3): 337-342. [CrossRef]

[47] Rochfort, KD, Collins LE, Murphy RP, Cummins PM. Downregulation of Blood-Brain Barrier Phenotype by Proinflammatory Cytokines Involves NADPH Oxidase-Dependent ROS Generation: Consequences for Interendothelial Adherens and Tight Junctions. PLoS One. 2014; 9(7): 101815.

[48] de Lores Arnaiz GR, Ordieres MG. Brain Na+, $\mathrm{K}^{+}$-ATPase Activity. In Aging and Disease. Int J Biomed Sci. 2014; 10(2): 85-102. [CrossRef]

[49] Kurauchi Y, Hisatsune A, Seki T, Katsuki H. Na(+), K(+)-ATPase dysfunction causes cerebrovascular endothelial cell degeneration in rat prefrontal cortex slice cultures. Brain Res. 2016; 1644: 249-57. [CrossRef]

[50] Goldblatt H, Lynch J, Hanzal RF, Summerville WW. Studies on Experimental Hypertension I. The production of persistent elevation of the systolic blood pressure by means of renal ischemia. Journal of Experimental Medicine. 1934; 59: 347-379. [CrossRef]

[51] Toklu HZ, Keyer Uysal M, Kabasakal L, Sirvanci S, Ercan F, Kaya M. The Effects of Riluzole on Neurological, Brain Biochemical, and Histological Changes in Early and Late Term of Sepsis in Rats. J Surg Res. 2009; 152: 238-48. [CrossRef]

[52] Kadığlu SB. PhD Thesis. The effect of Myrtus communis subsp. communis on cognitive and neuronal functions of postmenopausal diabetic rats. Department of Pharmacology, Faculty of Pharmacy, Marmara University, Haydarpaşa, İstanbul, Turkey, 2017. 